\title{
The monitoring of atmospheric mercury species in the Southern Indian Ocean at Amsterdam Island (38 $\left.{ }^{\circ} \mathrm{S}\right)$
}

\author{
M. Barret ${ }^{1}$, A. Dommergue ${ }^{1}, \underline{\text { C.P. Ferrari }}^{1}$ and O. Magand ${ }^{1}$ \\ ${ }^{1}$ UJF - Grenoble 1 / CNRS, Laboratoire de Glaciologie et Géophysique de l'Environnement (LGGE) UMR 5183, \\ Grenoble, F-38041, France dommergue@lgge.obs.ujf-grenoble.fr
}

\begin{abstract}
The role of oceans in the global cycle of mercury is still poorly characterized, mainly because of a lack a long-term data on atmospheric mercury concentrations in the remote Southern Ocean. In the frame of GMOS (Global Mercury Observation System), we present here the first results from a new monitoring station at Amsterdam Island in the Southern Indian Ocean. For the period January to April 2012, we recorded mean concentration of gaseous elemental mercury (GEM), reactive gaseous mercury (RGM) and particulate-bounded mercury ( $\mathrm{PHg}$ ) of $1.03 \mathrm{ng} \mathrm{m}^{-3}, 0.37$ and $0.34 \mathrm{pg} \mathrm{m}^{-3}$ respectively. While GEM concentrations showed little variations, $\mathrm{RGM}$ and $\mathrm{PHg}$ exhibited fast variations with alternation of value below the instrumental detection limit and maximum values up to $4 \mathrm{pg} \mathrm{m}^{-3}$.
\end{abstract}

Key words: Atmospheric gaseous elemental mercury, Reactive Gaseous Mercury, southern hemisphere, GMOS, marine boundary layer.

\section{Introduction}

Mercury $(\mathrm{Hg})$ is a worldwide pollutant, which can cause severe problems to environment and human health. Mercury is emitted into the atmosphere from a variety of anthropogenic and natural sources. Fossil fuel combustion, smelting, cement production and waste incineration are the major anthropogenic sources, while the oceans reemission to the atmosphere is the largest natural source.

$\mathrm{Hg}$ is mostly emitted to the atmosphere as gaseous elemental mercury (GEM). GEM has an estimated mean tropospheric residence time of about 1 year, which makes mercury prone to long-range atmospheric transport at the global scale. GEM can be oxidized by species such as ozone, hydroxyl or halogens radicals (Holmes et al., 2010; Pal and Ariya, 2004; Stephens et al., 2012). GEM oxidation results in divalent species ( $\mathrm{Hg}(\mathrm{II}))$ production. $\mathrm{Hg}$ (II) species are very soluble and can be therefore deposited by precipitation, or incorporated to particulate matter (PHg). Among $\mathrm{Hg}$ (II) species, reactive gaseous mercury (RGM) is operationally defined as mercury collected by a $\mathrm{KCl}$ denuder tube.

One current issue in the understanding of mercury recycling at the global scale is the role of oceans. Modeling studies suggest that net GEM reemission from oceans can account for more than $2000 \mathrm{Mg} \mathrm{yr}^{-1}$ while the deposition of $\mathrm{Hg}(\mathrm{II})$ species to oceans can account for
$3600 \mathrm{Mg} \mathrm{yr}^{-1}$ (Selin et al., 2007; Strode et al., 2007; Holmes et al., 2010). The presence of sea salt particle over oceans can greatly enhance the deposition of $\mathrm{Hg}$ (II), accounting for $35 \%$ of the global $\mathrm{Hg}$ (II) deposition to oceans. Relatively few observations of atmospheric $\mathrm{Hg}$ have been carried out in the Southern Hemisphere.

The few representative observations of remote atmosphere in the Southern Hemisphere to date consists essentially in oceanographic campaigns or grounded base measurement at Cape Point in South Africa (Slemr et al., 2011; Brunke et al., 2010). For nearly all other Southern American observations, TGM (Total Gaseous Mercury defined as the sum of gaseous mercury species) concentrations were substantially greater than the accepted global background level (Ebinghaus et al., 2007; Lacerda and Marins, 1997; Brunke et al., 2010), because they have been carried out near to, or downwind of major sources. This includes mining, industrial facilities and biomass fires.

Recent modeling study also pointed out the lack of atmospheric and deposition data to discriminate the processes that are responsible for low GEM concentrations in the Southern mid-latitudes (Holmes et al., 2010). In this context, we set up a monitoring station for atmospheric mercury speciation at Amsterdam Island, a remote island in the Southern part of the Indian Ocean. With this continuous data set, we will provide with the very first ground-based dataset that is exclusively influenced by oceanic air masses of the Southern 
Hemisphere.

\section{Materials and Methods}

\section{Site Description}

Amsterdam Island is a small island $\left(55 \mathrm{~km}^{2}\right)$ located in the Indian Ocean $3400 \mathrm{~km}$ far from Madagascar. Its remote position makes this site isolated from local anthropogenic emissions. Climate at Amsterdam Island is mild oceanic, with frequent presence of cloud. Air temperature varies from $11^{\circ} \mathrm{C}$ in August with $17^{\circ} \mathrm{C}$ in February. Moisture is important with values above $80 \%$ most of the year. Precipitations are very frequent with an average of 239 days with rain, for a total precipitation of $1114 \mathrm{~mm}$ over the year.

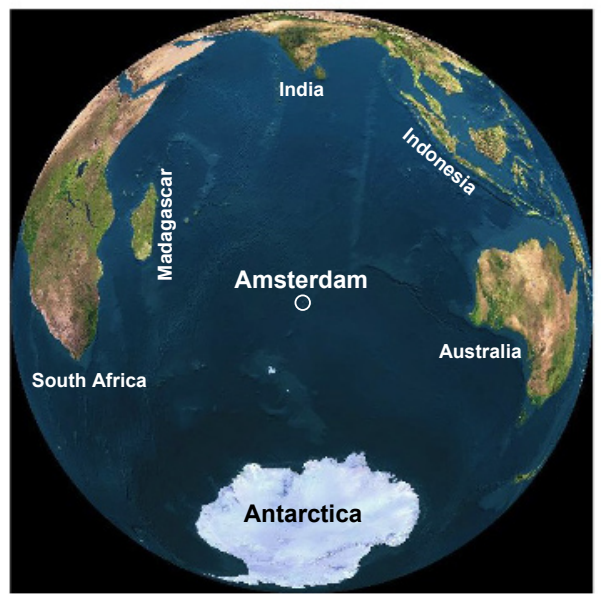

Figure 1. Orthographic projection centered over Amsterdam Island.

Measurements are performed at Pointe Bénédicte station, which is located $2 \mathrm{~km}$ west of the Saint Martin de Viviès base on the edge of a cliff $55 \mathrm{~m}$ above sea level (GPS coordinates: $37,79604^{\circ} \mathrm{S}, 77.55095^{\circ} \mathrm{E}$ ). This site is also part of other atmospheric monitoring programs such as GAW, AEROTRACE, RAMCES and CESOA.

\section{Mercury Measurements}

Atmospheric mercury speciation measurements are carried out using Tekran 2537B gas-phase mercury vapor analyzer and Tekran 1130-1135 speciation units. The analytical method is based on the amalgamation of mercury onto a gold trap, followed by thermal desorption and detection by cold vapor atomic fluorescence spectrometry (CVAFS) at $253.7 \mathrm{~nm}$. The detection is performed by the Tekran 2537 at sub ng $\mathrm{m}^{-3}$ levels. This device uses a dual cartridge design that allows alternative sampling and desorption, resulting in a continuous measurement of mercury in the air stream. To protect the 2537B gold cartridges, the air stream passes through a SodaLime trap and a $0.2 \mu \mathrm{m}$ PTFE filter before reaching the instrument.

Tekran 1130 and 1135 units are located on the roof top of the laboratory and connected to the 2537B analyzer by a $5 \mathrm{~m}$ long heated line $\left(50^{\circ} \mathrm{C}\right)$. The sampling inlet is situated $6 \mathrm{~m}$ above the ground. A 3-hour sampling period is used for RGM and $\mathrm{PHg}$ collection. During the collection period, GEM is measured on a 5-min time step by the $2537 \mathrm{~B}$ analyzer while RGM is collected on a potassium chloride coated quartz annular denuded housed in the Tekran 1130 and $\mathrm{PHg}$ is trapped on a quartz regenerable particulate filter (RPF) housed in the 1135 unit. Sample flow during collection is $10 \mathrm{~L} \mathrm{~min}^{-1}$ (STP) which allows the inlet impactor to reach a cutoff diameter of $2.5 \mu \mathrm{m}$. Following 3 -h sampling periods, the whole instrumental sampling train is flushed with mercury free and dry air provided by the Tekran 1130 Pump module pumping through a 1102 air dryer unit. Then, the particulate filter is heated to $800^{\circ} \mathrm{C}$, resulting in the release of $\mathrm{PHg}$ as GEM, analyzed subsequently by the Tekran 2537B. Once PHg quantified, the denuder is heated to $500^{\circ} \mathrm{C}$ and $\mathrm{RGM}$ is analyzed as GEM by the analyzer. The analysis of $\mathrm{PHg}$ and RGM takes $1 \mathrm{~h}$ resulting in a complete instrumental cycle of operation of $4 \mathrm{~h}$. To ensure clean operations and efficient collection of RGM and $\mathrm{HgP}$, denuder, RPF, SodaLime and filters are changed on a biweekly to monthly basis with a weekly visit. Automatic calibration using the $2537 \mathrm{~B}$ intern permeation source is performed every 68 hours. The Tekran 2537B, 1130 pump and 1102 air dryer are installed in an air conditioned laboratory where GEM is below $10 \mathrm{ng} \mathrm{m}^{-3}$ (typically $7 \mathrm{ng} \mathrm{m}^{-3}$ ) with all devices running on.

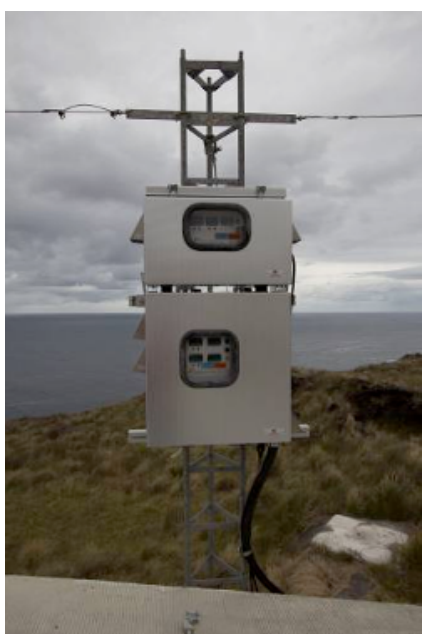

Figure 2. Tekran front-end modules 1130 and 1135 installed on the roof Pointe Benedicte's laboratory at Amsterdam Island.

\section{Quality Check and Data Processing}

The Tekran 2537B outputs one data measurement every 5 minutes when running. These data need to be processed to calculate $\mathrm{RGM}$ and $\mathrm{PHg}$ concentrations. When routine maintenances are performed these periods also need to be removed from the data.

To make it easier to manage the data, we specifically developed software programs. The first one helps the site managers to perform weekly inspections and routine maintenances. It also records the proper performance of the instruments. When maintenance is performed, date, time and glassware change as well as 
any other intervention are indicated and archived in an electronic file. This routine file is sent to the site supervisor with Tekran data. Data files from Tekran 2537B are then processed along with routine files for QA/QC. Briefly, this QA/QC is based on data validation or invalidation and data flagging to produce clean time series for GEM, RGM and PHg. Automatic calibration reports are split from these time series for a specific analysis. Our screening criteria are inspired by those used by AMNet (http://nadp.sws.uiuc.edu/amn/). For example, the first two GEM measurements following a desorption cycle are automatically removed. These measurements suffer from a negative bias due to dilution with mercury free air. GEM data following routine maintenance period along with the first desorption cycle following glassware change are also removed. Suspicious concentrations are also reported by a warning flag that can manually be overridden. Finally, the site supervisor can invalidate any data, for example if local contamination is suspected.

\section{Results and Discussion}

We present here data from 28 January to 23 April 2012, representing 2076 hours of measurements. During this period, validated data represents $90 \%$ of the total data $\left(\mathrm{n}_{\mathrm{GEM}}=16256, \mathrm{n}_{\mathrm{RGM}}=498, \mathrm{n}_{\mathrm{PHg}}=468\right) .47 \%$ of invalidated data is due to power failure or acquisition problem including crashes of dedicated computer. The exclusion of first two GEM measurements after a desorption cycle accounts for $41.7 \%$ of invalidated data. Period of routine maintenance only covers $8.4 \%$ of invalidated data. Because there is no sampling during the analysis of $\mathrm{RGM}$ or $\mathrm{PHg}$ and during automatic calibrations, about $26 \%$ of the total time period is not covered by measurements.

Validated data are plotted in Figure 1 where GEM are reported on a 5 minutes time basis while $\mathrm{RHg}$ and $\mathrm{PHg}$ points represent the concentration of the past 3 hours of sampling. As shown in this figure, GEM concentration is very steady with a mean value of $1.03 \pm 0.03 \mathrm{ng} \mathrm{m}^{-3}$. This value is well within the range expected for a remote marine site in the Southern Hemisphere. In comparison, Witt et al. (2010) measured GEM concentration of $1.2 \mathrm{ng} \mathrm{m}^{-3}$ in the Indian Ocean at latitudes between 9 and $21^{\circ} \mathrm{S}$, while Brunke et al. (2010) report mean concentration of $0.9 \mathrm{ng} \mathrm{m}^{-3}$ at Cape Point station $\left(34^{\circ} 21^{\prime} \mathrm{S}, 18^{\circ} 29^{\prime} \mathrm{E}\right)$.

RGM and PHg exhibit a very different behavior with a strong variability, although concentrations measured are very low with an average of $0.37 \pm 0.47 \mathrm{pg}$ $\mathrm{m}^{-3}$ and $0.34 \pm 0.49 \mathrm{pg} \mathrm{m}^{-3}$ for RGM and $\mathrm{PHg}$, respectively. About $23 \%$ and $29 \%$ of data for RGM and PHg could not be quantified by the instrument and were reported as 0 concentrations. It is to be noted that the maximum values recorded are only 3.9 and $4.1 \mathrm{pg} \mathrm{m}^{-3}$. Such low values for $\mathrm{RGM}$ and $\mathrm{PHg}$ at Amsterdam Island could be explained by the very frequent drizzles efficiently scavenging oxidized mercury species. To further investigate this possibility, a precipitation collector will be set up before the end of 2012 in order to measure mercury concentration in rain.

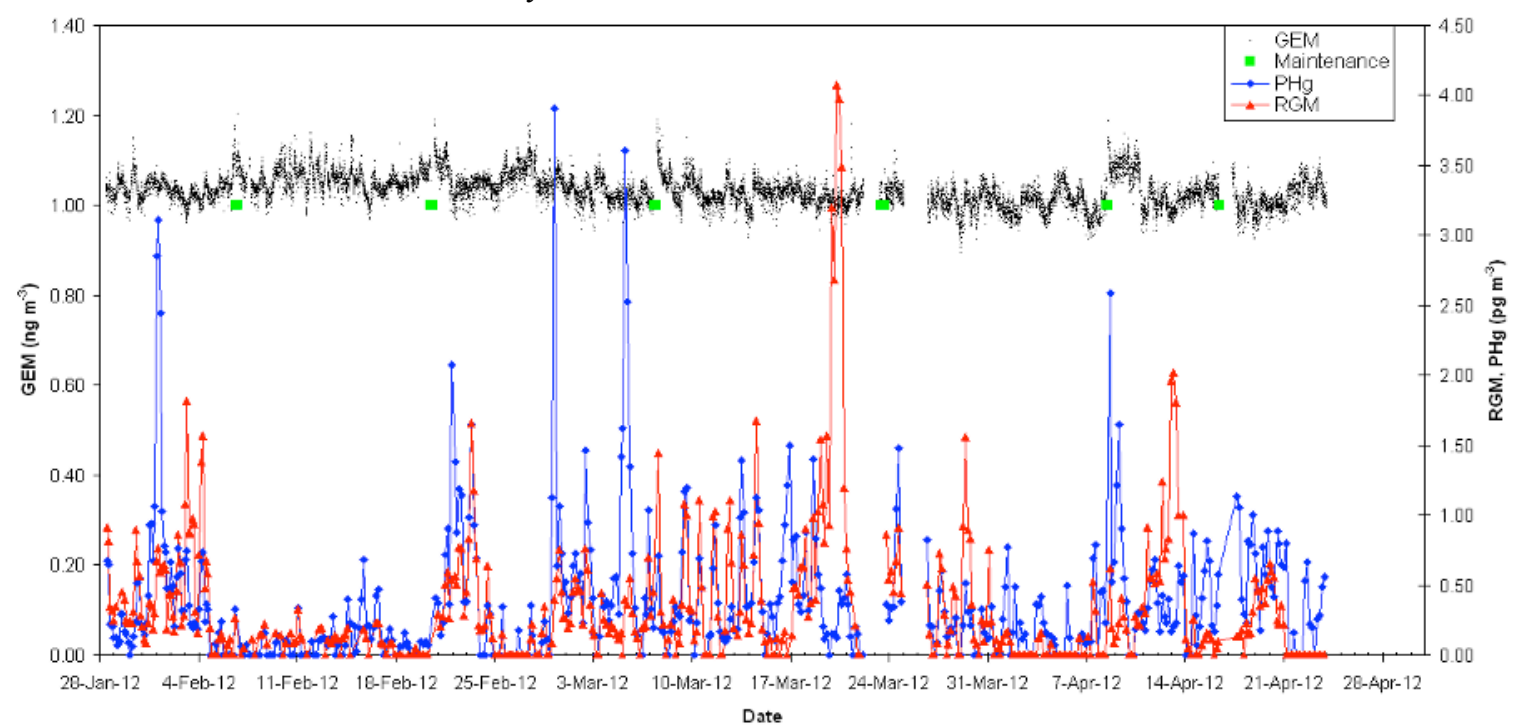

Figure 2. Time series of GEM (black dots), RGM (red triangles) and PHg (blue diamonds) recorded at Amsterdam Island. Routine maintenances are also reported on the figure (green squares).

\section{Conclusion}

For the first time, mercury speciation data were recorded land-based station in the Southern Hemisphere mid-latitudes. The first 4 months of atmospheric measurements have shown little variations in GEM $\left(1.03 \pm 0.03 \mathrm{ng} \mathrm{m}^{-3}\right)$ but concentrations in $\mathrm{RHg}$ and $\mathrm{PHg}$ at a very low level $\left(<4 \mathrm{pg} \mathrm{m}^{-3}\right)$. Such low concentration could indicate efficient deposition pathways of mercury species. Measurement of atmospheric mercury species at Amsterdam Island will continue and will be soon backed up by collection of precipitation for mercury analysis. We believe that the dataset provided by such a station will provide new relevant data in order to better understand processes affecting the mercury 
cycle over oceans.

\section{Acknowledgements}

This work contributes to the EU-FP7 project Global Mercury Observation System (GMOS). Logistical, technical and financial support were also provided by the French Polar Institute IPEV (Program 1028, GMOStral). We gratefully acknowledge the two winterovering staff Boris Bouillard and Erwan $\mathrm{Coz}$ for their field work on Tekran units. The CNRS LEFE-CHAT (program SAMOA) and the Labex OSUG@2020 (program OMARAS) financially contributed to this action. AD is grateful to the Institut Universitaire de France. We want to acknowledge AEROTRACE (J Sciare) and CESOA for their help to plan our project. We deeply thank Mark Olson from AMNET, Eric Prestbo and Lucas Hawkins from Tekran for useful discussions.

\section{References}

Brunke E, Labuschagne C, Ebinghaus R, Kock HH, Slemr F. Gaseous elemental mercury depletion events observed at Cape Point during 2007 2008. Atmospheric Chemistry and Physics 2010:1121-31.

Ebinghaus R, Slemr F., Brenninkmeijer C a. M, van Velthoven P, Zahn a., Hermann M, O'Sullivan D a., Oram DE. Emissions of gaseous mercury from biomass burning in South America in 2005 observed during CARIBIC flights. Geophysical Research Letters 2007;34:1-5.

Holmes CD, Jacob D J, Corbitt ES, Mao J, Yang X,
Talbot R, Slemr F. Global atmospheric model for mercury including oxidation by bromine atoms. Atmospheric Chemistry and Physics 2010;10:12037-57.

Lacerda LD, Marins RV. Anthropogenic mercury emissions to the atmosphere in Brazil: The impact of gold mining. Journal of Geochemical Exploration 1997;58:223-9.

Pal B, Ariya PA. Studies of ozone initiated reactions of gaseous mercury: kinetics, product studies, and atmospheric implications. Physical Chemistry Chemical Physics 2004;6:572.

Selin NE, Jacob Daniel J, Park RJ, Yantosca RM, Strode S, Jaeglé L, Jaffe D. Chemical cycling and deposition of atmospheric mercury: Global constraints from observations. Journal of Geophysical Research 2007;112:D02308.

Slemr F., Brunke E-G, Ebinghaus R, Kuss J. Worldwide trend of atmospheric mercury since 1995. Atmospheric Chemistry and Physics 2011;11:4779-87.

Stephens CR, Shepson PB, Steffen A, Bottenheim JW, Liao J, Huey LG, et al. The relative importance of chlorine and bromine radicals in the oxidation of atmospheric mercury at Barrow, Alaska. Journal of Geophysical Research 2012;117:D00R11.

Strode S a., Jaeglé L, Selin NE, Jacob Daniel J., Park RJ, Yantosca RM, Mason RP, Slemr Franz. Air-sea exchange in the global mercury cycle. Global Biogeochemical Cycles 2007;21:1-12.

Witt MLI, Mather T a., Baker AR, De Hoog JCM, Pyle DM. Atmospheric trace metals over the south-west Indian Ocean: Total gaseous mercury, aerosol trace metal concentrations and lead isotope ratios. Marine Chemistry 2010;121:2-16. 